\title{
Endothelin-1 and angiotensin-II modulate urotensin-II vasoconstriction in rat aorta exposed to mercury
}

\author{
Ahmed AH, Maulood IM \\ Department of Biology, College of Science, Salahaddin University, Erbil, Iraq. \\ Ahmed.hasan@den.hmu.edu.iq
}

\begin{abstract}
OBJECTIVES: The aim of this study was to evaluate the possible roles of endothelin-1 and angiotensin-II in urotensin-II vasoconstriction and in endothelial dysfunction induced by mercury.

BACKGROUND: Urotensin-II, the most potent vasoactive peptide, is entwined with the cardiovascular diseases and has been labelled as a new pathophysiological biomarker.

METHODS: Rat aortic rings were pre-incubated with sb-710411, bq-123, and captopril. Doses of human urotensin-Il with increased concentrations were applied in all groups in the presence or absence of mercury chloride. In another set of the experiment, aortic rings were treated with a single dose of mercury chloride in the presence of each of the above blockers.

RESULTS: Angiotensin-II and endothelin-1 mediated the vascular responses to the peptide urotensin-II under conditions of both intact endothelium and endothelial impairments induced by mercury. Urotensin-II, angiotensinII and endothelin-1 significantly participated in vascular responses to mercury chloride.

CONCLUSION: The novel finding was that urotensin-II is potentiated under the condition of endothelial dysfunction. Endothelin-1 and angiotensin-II pathways could be heavily exploited in modulating endothelial dysfunction impacts and peptide vascular actions (Tab. 1, Fig. 4, Ref. 30). Text in PDF www.elis.sk.

KEY WORDS: urotensin-II, endothelial dysfunction, angiotensin-II, endothelin-1, mercury chloride.
\end{abstract}

\section{Introduction}

In the past two decades, the cyclic peptide, urotensin-II (UII), has been emphasized as the most potent mammalian vasoconstrictor so far. This startling peptide which had been isolated for the first time from the neurosecretory system of a teleost fish (Gillichthys mirabilis) (1), has variable effects on different tissues and organs (1-3). The available cumulative evidence uncovers that the UII vascular actions depend on species, blood vessel type, and endothelial integrity (4). Currently, UII contributes to cardiovascular dysfunction (5-7), oxidative stress (8), diabetic cardiomyopathy (9), pulmonary fibrosis (3), and metabolic syndrome (10). Urotensin-II receptor (UT2) has been cloned in different tissues and organs of most mammals $(11,12)$. The endothelial impairment is concurrently traced by elevated levels of angiotensin-II (ang-II) (13), endothelin-1 (et-1) (14) and vasoconstrictive prostanoids (15), and has been addressed as the main factor involved in cardiovascular diseases (16). Mercury, a potent toxic metal (17) that has hiddenly been in contact with human beings in both industrial and medical applications (18),

Department of Biology, College of Science, Salahaddin University, Erbil, Iraq

Address for correspondence: A.H. Ahmed, Mantikawa Street, College of Science, Erbil, Iraq, Postal ID: (44002)

Phone: +9647504654820 is accused of being a potent endothelial impairment inducer (19, $20)$. However, endothelial damage followed by a release of endothelial vasoactive factors seems to be one of the recognized themes of mercury toxicity both in vivo and in vitro studies (21). According to our knowledge, no evidence is available yet about the possible endothelial dysfunction impact on the vascular response to UII. In this study, we argue that UII vascular action is potentiated under condition of endothelial dysfunction and might involve et-1 and ang-II.

\section{Materials and methods}

\section{Chemicals}

Human UII (hUII) and sb-710411 were purchased from Bachem (Bubendorf, Zwitzerland). Mercury chloride $\left(\mathrm{HgCl}_{2}\right)$, bq-123 and captopril were purchased from Scharlab S.L/Sentmenat, Spain.

\section{Aortic rings preparations}

Animals

Male Wister rats weighing (200-250 g) were purchased from Directorate of Duhok Veterinary Duhok/Iraq. Animals were housed in animal house and kept in standard conditions according to the laboratory animal care guide prepared by the scientific committee in College of Science, Slahaddin University. The study was carried out at the Biology Department, College of Science, from 
Tab. 1. The potency differences $\left(\mathrm{pD}_{2}\right)$ and maximum response $\left(\mathrm{E}_{\max }\right)$ to $\mathrm{hU}-\mathrm{II}$ in the presence and absence of $\mathrm{HgCl}_{2}$ from rat thoracic aorta.

\begin{tabular}{|c|c|c|c|c|}
\hline & \multicolumn{2}{|c|}{ Untreated } & \multicolumn{2}{|c|}{$\mathrm{HgCl}_{2}$-treated } \\
\hline & $\mathrm{E}_{\max } \% \mathrm{KCL}$ & $\mathrm{pD}_{2}$ & $\mathrm{E}_{\max } \% \mathrm{KCL}$ & $\mathrm{pD}_{2}$ \\
\hline Control & $74.83 \pm 2.46$ & $-8.782 \pm 0.077$ & $105.2 \pm 5.392$ & $-8.744 \pm 0.119$ \\
\hline Sb-710411 & $37.75 \pm 1.78 * * *$ & $-8.560 \pm 0.098$ & $101.6 \pm 7.071$ & $-8.827 \pm 0.179$ \\
\hline Captopril & $20.93 \pm 1.291 * * *$ & $-8.633 \pm 0.1363$ & $61.76 \pm 8.307 * * *$ & $-7.877 \pm 0.203^{*}$ \\
\hline $\mathrm{Bq}-123$ & $114.8 \pm 9.103 * * *$ & $-8.521 \pm 0.163$ & $80.55 \pm 6.802$ & $-8.533 \pm 0.176$ \\
\hline
\end{tabular}

The studied groups were compared with the control group (ANOVA was applied with Dunnet test).

* Significant differences between the studied groups vs control group at $\mathrm{p}<0.05$

$* * *$ Significant differences between the studied groups vs control group at $\mathrm{p}<0.001$

January, 2017 to August, 2017, and the animal care committee approved the study.

\section{Aortic rings preparation}

In this study, 88 aortic rings from 22 male Wister rats were used. Animals were anaesthetized by ketamine: xylazine mixture (90 mg/kg, i.p. and $10 \mathrm{mg} / \mathrm{kg}$, i.p., respectively) (22). From the proximal descending thoracic aorta (23), immediately next to the left subclavian branch, a 12-mm long piece was isolated in cold Krebs solution and cleaned from excessive surrounding tissues; then 4 aortic rings, each about $3 \mathrm{~mm}$ in length, were prepared.

\section{Vascular reactivity assay}

The prepared aortic segments were held by stainless steel hooks in 10-ml organ bath (Automatic organ bath-Panlab Harvard apparatus-USA, AD Instrument PowerLab 8/35-Australia) filled with Krebs bicarbonate solution (in $\mathrm{mM} / \mathrm{L}: 119 \mathrm{NaCl}, 4.7 \mathrm{KCl}$, 1.2 $\mathrm{MgSO}_{4}, 1.2 \mathrm{KH}_{2} \mathrm{PO}_{4}, 1.5 \mathrm{CaCl}_{2}, 25 \mathrm{NaHCO}_{3}, 11$ glucose; $\mathrm{pH}$ =7.4). The bath solution was maintained at $37^{\circ} \mathrm{C}$ and bubbled with a mixture of about $95 \% \mathrm{O}_{2}$ and $5 \% \mathrm{CO}_{2}$. The aortic rings were loaded by a tension force of $2 \mathrm{~g}$ and allowed to equilibrate for at least $1 \mathrm{hr}$ during which the Krebs solution was replaced every 15 minutes, and the tension was continuously readjusted to the optimum force. For the functional integrity of the prepared aortic segments, $\mathrm{KCl}(60 \mathrm{mM})(24)$ was used while the maximum contraction developed was considered to represent the standard percentage contractile response. Then the aortic rings were washed and re-stabilized at the optimum tension for at least 30 minutes before applying any vasoactive substances. In one group, the endothelium was removed by gently rubbing the lumen of the aortic rings with a tip of narrow forceps, and the denuded rings were assessed by adding acetylcholine $(10 \mu \mathrm{M})$ to pre-contracted aortic segments with noradrenaline $(1 \mu \mathrm{M})$.

\section{Experimental procedures}

The study was designed to evaluate the possible contribution of some vasoactive peptides to the vascular action of UII in the presence or absence of $\mathrm{HgCl}_{2}$. Thereby, two parallel sets of experiments were carried out as follows:

Set 1: To investigate the roles of different vasoactive factors on hUII-elicited vascular contraction in endothelial impairment, the intact aortic rings were incubated for $20 \mathrm{~min}$ with a selective UT-2 receptor antagonist, sb-710411 $(1 \mu \mathrm{M})$, angiotensin-converting enzyme (ACE) inhibitor, captoprole $(10 \mu \mathrm{M})$ and selective et-1 receptor type $\mathrm{A}\left(\mathrm{ET}_{\mathrm{A}}\right)$ blocker, bq-123 $(0.3 \mu \mathrm{M})$. Then, doses with increased concentrations of hUII $\left(10^{-11}-10^{-8} \mathrm{M}\right)$ were applied to all groups in the presence or absence of $\mathrm{HgCl}_{2}$.

To estimate the half effective concentration $\left(\mathrm{EC}_{50}\right)$ of $\mathrm{HgCl}_{2}$, doses with increased concentrations of $\mathrm{HgCl}_{2}\left(10^{-9}-10^{-3}\right)$ were applied, and the estimated $\mathrm{pD}_{2}$ value was applied in another set of experiment as a single dose in the time-dependent vascular response to $\mathrm{HgCl}_{2}$.

In another set of the experiment that is aimed at studying the possible involvement of UII, ang-II, and et-1 in time-dependent vasoconstriction effects of a single dose of $\mathrm{HgCl}_{2}$, the isolated aortic rings were pre-incubated with Sb-710411, captopril, or bq-123 for 20 min prior to the application $(3 \mu \mathrm{M})$ of $\mathrm{HgCl}_{2}$; then acetylcholine $(10 \mu \mathrm{M})$ was added to check the endothelial impairment induced by mercury.

\section{Statistical analysis}

Vasoconstrictor responses induced by hU-II were expressed as percentages of tension generated by $60 \mathrm{mM} \mathrm{KCl}$. To differentiate the effect of drugs on vascular responses to hU-II in thoracic aortic segments from both control and $\mathrm{HgCl}_{2}$-treated groups, the data are expressed as mean \pm standard error of means (SEM) of the number of animals used in all groups. To compare the control and studied groups, the two-way analysis of variance (ANOVA) was applied, and Sidak post hoc test was used to compare individual means. Dunnets t-test was also applied to compare $\mathrm{pD}_{2}$ between studied drugs with controls. Differences were considered statistically significant at $\mathrm{p}<0.05$.

\section{Results}

\section{Effect of mercury on vascular response to hUII}

The present results showed that mercury treatment remarkably potentiated the vascular response to the peptide and increased the maximum response (Tab. 1) while the hUII potency remained significantly unchanged (Fig. 1).

In the present study we determined the half effective concentration $\left(\mathrm{EC}_{50}\right)$ of $\mathrm{HgCl}_{2}$ as $(3 \mu \mathrm{M})$ (Fig. 2) which was applied as a single dose for the time-dependent vascular response test. The aortic rings in all mercury-treated groups, at the end of each experimental group, did not respond to $10 \mu \mathrm{M}$ acetylcholine which indicated that the successive endothelial impairment was caused by the applied dose of $\mathrm{HgCl}_{2}$. 


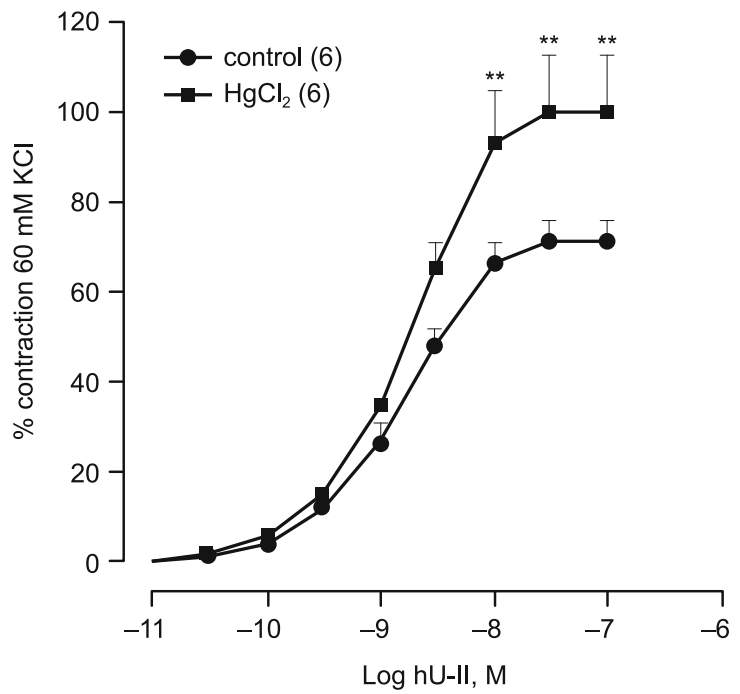

Fig. 1. The effects of $\mathrm{HgCl}_{2}$ on the vasocular responses to $\mathrm{hU}-\mathrm{II}$ from rat proximal thoracic aortic rings. The double asterisks ** represents the statistical differences at $\mathbf{P}<\mathbf{0 . 0 1}$. Number of aortic rings used is indicated in parentheses.

Effect of sb-710411, captopril or bq-123 on vascular response to hUII: effects of mercury

The selective UT receptor antagonist (sb-710411) highly significantly reduced the efficacy of hUII with no significant changes in the peptide potency (Tab. 1), while in the presence of mercury, interestingly, the antagonist failed to dampen the peptide vasoconstriction effects (Fig. 3A). Another novel findings in this study was that captopril highly significantly reduced the peptide efficacy in both mercury-treated and untreated groups (Fig. 3B). On the other hand, the present results revealed that the selective et-1 receptor antagonist highly significantly potentiated the vascular responses to hUII (Fig. 3C) while increasing the contraction altitude. Meanwhile, in the presence of mercury, vascular responses to hUII were significantly unchanged in bq-123-treated groups (Tab. 1).

The roles of sb-710411, captopril or bq-123 in the vascular responses to a single dose of $\mathrm{HgCl}_{2}$

The results showed that pre-incubation of aortic rings with sb-710411 caused a significant decrease in vascular responses to $\mathrm{HgCl}_{2}$ and shifted the response curve to the right (Fig. 4A), while captopril caused a highly significant reduction in the vascular responses to mercury (Fig. 4B). On the other hand, a remarkable significant decrease in vascular responses to $\mathrm{HgCl}_{2}$ were also observed in aortic rings treated with bq-123 (Fig. 4C).

\section{Discussion}

While sb-710411 was known as one of the effective UII antagonists used in many studies $(25,26,27)$, in the present study, for the first time, we demonstrated that under endothelial impairment status, the vasoconstriction effect of UII is inevitable, while reflecting that endothelial impairment sustained the peptide vasoactive

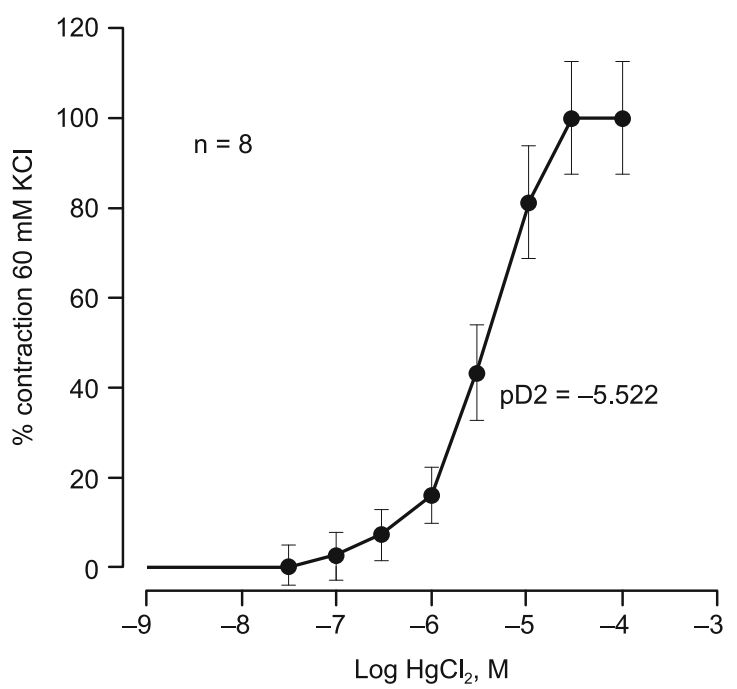

Fig. 2. The vascular responses to the cumulative doses of $\mathrm{HgCl}_{2}\left(\mathbf{1 0}^{-8}\right.$ $\left.-10^{-4} \mathrm{M}\right)$ from rat proximal thoracic aorta. Number of aortic rings used is indicated in parentheses.

capacity and under these circumstances, the UII receptors could not been blocked by the selected antagonist, probably due to the direct effects of mercury on the receptor protein moieties (21) that had somehow been distorted and lost some of their physiological properties. Another novel finding in the present study was that inhibition of ACE pathway not only abolished the vascular responses to hU-II, but also remarkably decreased the effects of mercury on vascular responses to hUII, thus indicating that angiotensin-II pathway plays a key role in both UII vasoconstriction and vascular impairment (15). Furthermore, the greater impact of captopril in mercury treatment indicated that the vasoconstriction-mediated endothelial impairment is mainly due to the angiotensin system, which is consistent with some recent studies $(15,28)$, while the extent of the impact of hUII was smaller. The increase in vascular responses to hUII in the bq-123-treated group was in contrast with the available evidence about the vasorelaxative and hypotensive effects of this antagonist $(29,30)$. However, we suggest that the selected dose of bq-123 might have non-selectively abolished the vasodilatory effects of the supposedly released endothelin-1 from hUII-treated group in the thoracic rat aorta and thus augmented the vascular actions of the peptide.

Seemingly, the implication of these vasoactive agents in endothelial impairment highlighted the mechanism taken by such toxic element to induce vascular impairment and probably unfolded a question as to which of vascular agents dominantly mediates the endothelial dysfunction impacts.

\section{Conclusions}

Endothelial impairment, that has been addressed in most pathological circumstances, distorts the vascular tone through the endothelial release of vasoactive substances and predominantly shifts 
un-treated

A

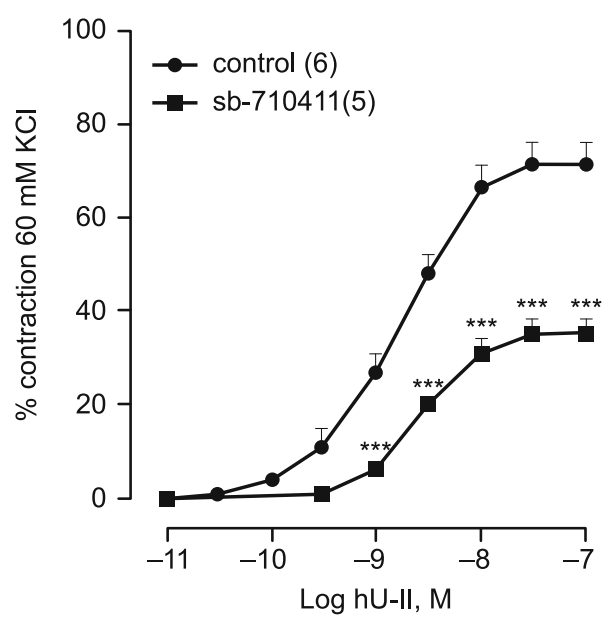

B

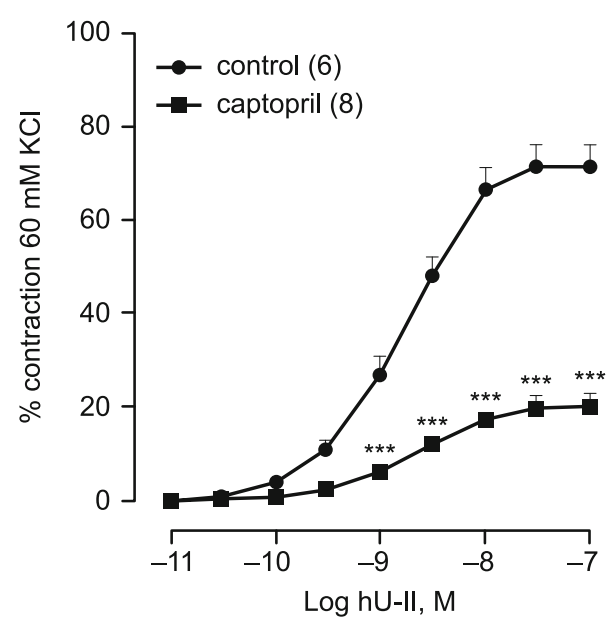

C

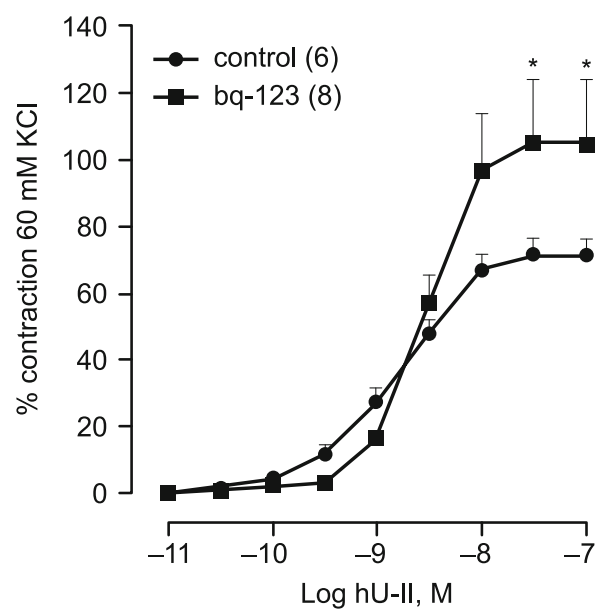

$\mathrm{HgCl}_{2}$-treated
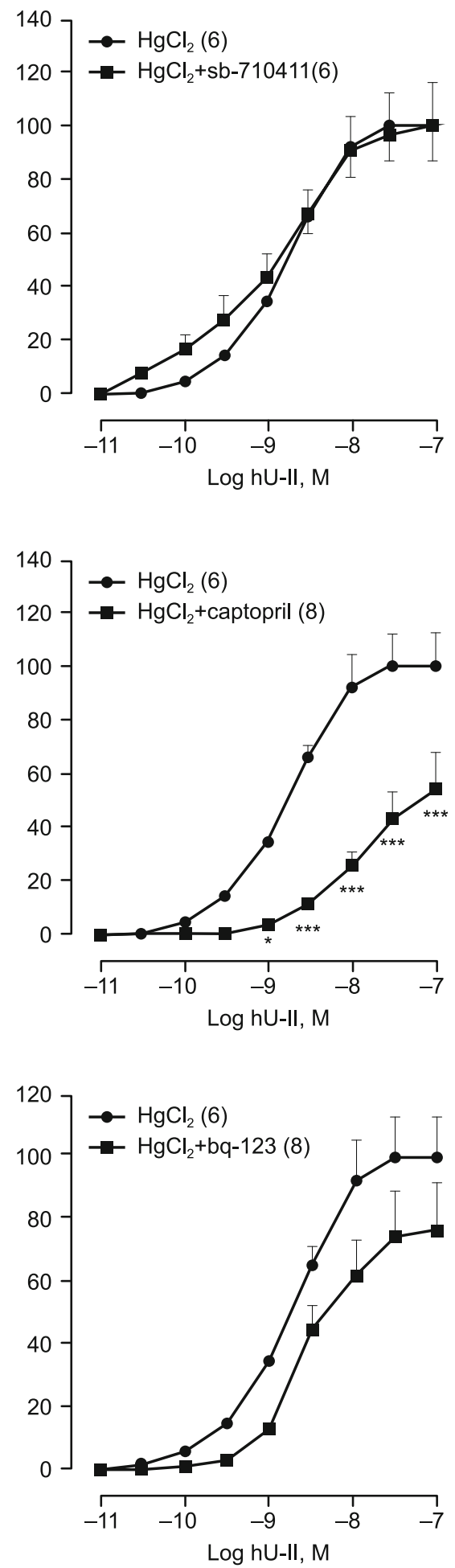

Fig. 3. Effects of A: sb-710411(1 $\mu \mathrm{M})$, B: captopril $(1 \mu \mathrm{M})$ and C: bq-123 $(10 \mu \mathrm{M})$ on the vasoconstriction responses to hU-II in the presence and absence of $\mathrm{HgCl}_{2}$ from rat thoracic aorta. The asterisks; ***,*** represent statistical differences at $\mathrm{P}<0.05, \mathrm{P}<0.01$ and $\mathrm{P}<0.001$, respectively, versus control group. Number of aortic rings used is indicated in parentheses. 
444-449
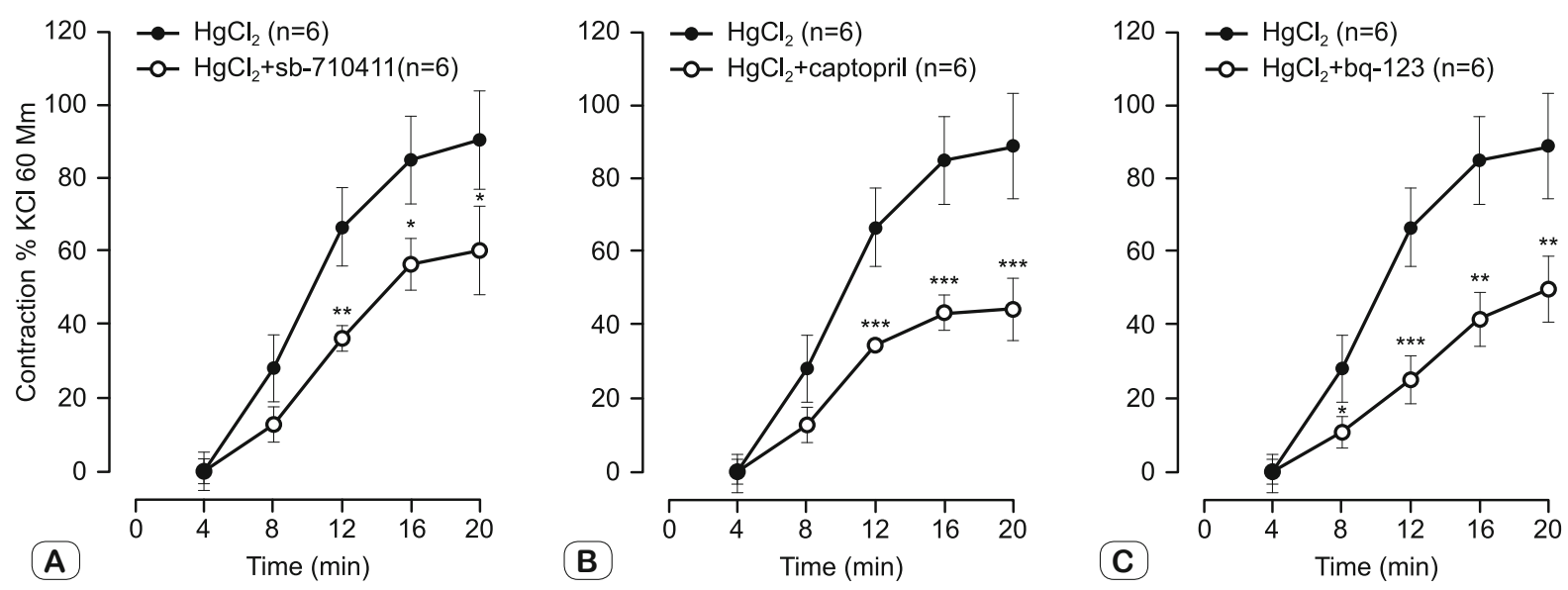

Fig. 4. The vascular responses to a single dose of $\mathrm{HgCl}_{2}(3 \mu \mathrm{M})$ in time dependent $(4,8,12,16$, and 20 min) from rat proximal thoracic aorta. Effects of A: sb-710411 $(1 \mu \mathrm{M})$, B: captopril $(1 \mu \mathrm{M})$ and C: bq-123 $(10 \mu \mathrm{M})$. Data are expressed as mean $\pm \mathrm{SE}$. The asterisks; *, **, *** represent statistical differences at $P<0.05, P<0.01$ and $P<0.001$, respectively, versus control group. Number of aortic rings used is indicated in parentheses.

it toward vasoconstriction. Urotensin-II, the weirdest vasoactive peptide, mediated the endothelial dysfunction and was accentuated by ang-II and et-1. An important point that one might consider is that endothelial impairment involves multi-vasoactive pathways, which further stresses the necessity to take these cellular routs to a great extent.

\section{References}

1. Debiec R, Christofidou P, Denniff M, Bloomer LD, Bogdanski P, Wojnar L et al. Urotensin-II system in genetic control of blood pressure and renal function. PLoS One 2013; 8 (12): e83137.

2. Wang H, Dong K, Xue X, Feng P, Wang X. Elevated expression of urotensin II and its receptor in diethylnitrosamine-mediated precancerous lesions in rat liver. Peptides 2011; 32 (2): 382-387.

3. Ding $\mathbf{Y}$, Lin $\mathbf{F}$, Chen $\mathbf{Y}$, Yan W, Wang $\mathbf{J}$, Chen $\mathbf{M}$ et al. Increased Expression of Urotensin II and Its Clinical Significance in Patients With Pulmonary Fibrosis. Chest 2016; 149 (4).

4. Al Kindi H, Hafiane A, You Z, Albanese I, Pilote L, Genest J et al. Circulating levels of the vasoactive peptide urotensin II in patients with acute coronary syndrome and stable coronary artery disease. Peptides 2014; 55: 151-157.

5. Albertin G, Guidolin D, Sorato E, Oselladore B, Tortorella C, Ribatti D. Urotensin-II-stimulated expression of pro-angiogenic factors in human vascular endothelial cells. Regul Pept 2011; 172 (1-3): 16-22.

6. Albertin G, Guidolin D, Sorato E, Spinazzi R, Mascarin A, Oselladore B et al. Pro-angiogenic activity of Urotensin-II on different human vascular endothelial cell populations. Regul Pept 2009; 157 (1-3): 64-71.

7. Brailoiu GC, Deliu E, Rabinowitz JE, Tilley DG, Koch WJ, Brailoiu E. Urotensin II promotes vagal-mediated bradycardia by activating cardiacprojecting parasympathetic neurons of nucleus ambiguus. J Neurochem 2014; 129 (4): 628-636.

8. Tabur S, Korkmaz H, Eren MA, Oguz E, Sabuncu T, Aksoy N. Urotensin-II level and its association with oxidative stress in early diabetic nephropathy. J Diabet Compl 2015; 29 (1): 115-119.
9. Dai H-Y, Guo X-G, Ge Z-M, Li Z-H, Yu X-J, Tang M-X et al. Elevated expression of urotensin II and its receptor in diabetic cardiomyopathy. J Diabet Compl 2008; 22 (2): 137-143.

10. Ong KL, Wong LY, Cheung BM. The role of urotensin II in the metabolic syndrome. Peptides 2008; 29 (5): 859-867.

11. Maguire JJ, Kuc RE, Kleinz MJ, Davenport AP. Immunocytochemical localization of the urotensin-II receptor, UT, to rat and human tissues: Relevance to function. Peptides 2008; 29 (5): 735-742.

12. Nguyen TT, Letourneau M, Chatenet D, Fournier A. Presence of urotensin-II receptors at the cell nucleus: specific tissue distribution and hypoxia-induced modulation. Int J Biochem Cell Biol 2012; 44 (4): 639-647.

13. Rahimmanesh I, Shahrezaei M, Rashidi B. High blood pressure and endothelial dysfunction: Effects of high blood pressure medication on endothelial dysfunction and new treatments. J Res Med Sci 2012; 17.

14. Donato AJ, Gano LB, Eskurza I, Silver AE, Gates PE, Jablonski $\mathbf{K}$ et al. Vascular endothelial dysfunction with aging: endothelin-1 and endothelial nitric oxide synthase. Amer J Physiol Heart Circulat Physiol 2009; 297 (1): H425-H432.

15. Angeli JK, Cruz Pereira CA, de Oliveira Faria T, Stefanon I, Padilha AS, Vassallo DV. Cadmium exposure induces vascular injury due to endothelial oxidative stress: the role of local angiotensin II and COX-2. Free Rad Biol Med 2013; 65: 838-848.

16. Bernatova I. Endothelial Dysfunction in Experimental Models of Arterial Hypertension: Cause or Consequence? BioMed Res Internat 2014; 2014: $1-14$

17. Fernandes Azevedo B, Barros Furieri L, Peçanha FM, Wiggers GA, Frizera Vassallo P, Ronacher Simões M et al. Toxic Effects of Mercury on the Cardiovascular and Central Nervous Systems. J Biomed Biotechnol 2012; 2012: 1-11.

18. Furieri LB, Galán M, Avendaño MS, García-Redondo AB, Aguado A, Martínez S et al. Endothelial dysfunction of rat coronary arteries after exposure to low concentrations of mercury is dependent on reactive oxygen species. Brit J Pharmacol 2011; 162 (8): 1819-1831. 
19. Morishita R, Rizzetti DA, Torres JGD, Escobar AG, Peçanha FM, Santos FW et al. Apocynin Prevents Vascular Effects Caused by Chronic Exposure to Low Concentrations of Mercury. PLoS ONE 2013; 8 (2).

20. Houston MC. Role of Mercury Toxicity in Hypertension, Cardiovascular Disease, and Stroke. J Clin Hypertens 2011; 13 (8): 621-627.

21. Bader M, Lemos NB, Angeli JK, Faria TdO, Ribeiro Junior RF, Vassallo DV et al. Low Mercury Concentration Produces Vasoconstriction, Decreases Nitric Oxide Bioavailability and Increases Oxidative Stress in Rat Conductance Artery. PLoS ONE 2012; 7 (11).

22. Rameshrad M, Babaei H, Azarmi Y, Fouladi DF. Rat aorta as a pharmacological tool for in vitro and in vivo studies. Life Sci 2016; 145: 190-204.

23. Chatenet D, Létourneau M, Nguyen QT, Doan ND, Dupuis J, Fournier A. Discovery of new antagonists aimed at discriminating UII and URP-mediated biological activities: insight into UII and URP receptor activation. Brit J Ppharmacol 2013; 168 (4): 807-821.

24. Qu Z, Zhang J, Gao W, Chen H, Guo H, Wang T et al. Vasorelaxant effects of Cerebralcare Granule $\AA$ are mediated by NO/cGMP pathway, potassium channel opening and calcium channel blockade in isolated rat thoracic aorta. J Ethnopharmacol 2014; 155 (1): 572-579.
25. Liu DG, Wang J, Zhang ZT, Wang Y. The urotension II antagonist SB-710411 arrests fibrosis in CCL4 cirrhotic rats. Mol Med Rep 2009; 2 (6): 953-961.

26. Zhao J, Ding W, Song N, Dong X, Di B, Peng F et al. Urotensin IIinduced collagen synthesis in cultured smooth muscle cells from rat aortic media and a possible involvement of transforming growth factor-beta1/ Smad2/3 signaling pathway. Regul Pept 2013; 182: 53-58.

27. Gallyas F, Luo S-Y, Chen S, Qin Y-D, Chen Z-W. Urotensin-IIReceptor Antagonist SB-710411 Protects Rat Heart against Ischemia-Reperfusion Injury via RhoA/ROCK Pathway. Plos One 2016; 11 (1).

28. Chiu CZ, Wang BW, Shyu KG. Angiotensin II and the JNK pathway mediate urotensin II expression in response to hypoxia in rat cardiomyocytes. J Endocrinol 2014; 220 (3): 233-246.

29. Hirt MN, Sörensen NA, Bartholdt LM, Boeddinghaus J, Schaaf S, Eder A et al. Increased afterload induces pathological cardiac hypertrophy: a new in vitro model. Basic Res Cardiol 2012; 107 (6): 307.

30. Torrens C, Seto SW, Krishna SM, Yu H, Liu D, Khosla S et al. Impaired Acetylcholine-Induced Endothelium-Dependent Aortic Relaxation by Caveolin-1 in Angiotensin II-Infused Apolipoprotein-E (ApoE-/-) Knockout Mice. PLoS ONE 2013; 8 (3).

Received February 20, 2918. Accepted March 23, 2018. 